\begin{tabular}{|c|c|c|}
\hline $\begin{array}{l}\text { PKS } \\
\text { PUBLIC } \\
\text { KNDOLLEGE } \\
\text { PROJECT }\end{array}$ & $\begin{array}{c}\text { REVISTA DE GEOGRAFIA } \\
\text { (RECIFE) } \\
\text { http://www.revista.uffe.br/revistageografia }\end{array}$ & $\begin{array}{l}\text { OJS } \\
\frac{\text { OPEN }}{\text { JOUNAL }} \\
\text { SYSTEMS }\end{array}$ \\
\hline
\end{tabular}

\title{
EVOLUÇÃO DO MODELADO DE RELEVO E DOS MATERIAIS NO SOPÉ DA ESCARPA DE CUESTA DE SÃO PEDRO-SP
}

\author{
Fernando Nadal Junqueira Villela ${ }^{1}$, Marcos Roberto Pinheiro ${ }^{2}$, José Pereira de Queiroz \\ Neto $^{3}$, Sidneide Manfredini ${ }^{4}$, Grace Bungenstab Alves ${ }^{5}$, André Mateus Barreiros ${ }^{6}$, Marcelo \\ Reis Nakashima ${ }^{7}$, Beatriz Ferraz Scigliano ${ }^{8}$, Cristiane Regina Michelon ${ }^{9}$, Antonio Artur dos \\ Santos $^{10}$, Andrio Filipe Amaral Soares ${ }^{11}$, Hellen Renata Guimarães Borsoi ${ }^{12}$, Georgea do \\ Vale de Melo $^{13}$, Rodrigo Ferreira Santos ${ }^{14}$
}

\footnotetext{
${ }^{1}$ Universidade de São Paulo. E-mail: geovillela@usp.br

${ }^{2}$ Universidade de São Paulo. E-mail: geografo_marcos@yahoo.com.br

${ }^{3}$ Universidade de São Paulo. E-mail: jpqneto@hotmail.com

${ }^{4}$ Universidade de São Paulo. E-mail: sidmanfredini@gmail.com

${ }^{5}$ Universidade Federal da Bahia. E-mail: gracebalves@gmail.com

${ }^{6}$ Universidade de São Paulo.E-mail: andrembarreiros@gmail.com

${ }^{7}$ Universidade de São Paulo. E-mail: mrnakashima@gmail.com

${ }^{8}$ Universidade de São Paulo. E-mail: biascigliano@gmail.com

${ }^{9}$ Instituto Federal Catarinense E-mail: cristianemichelon@yahoo.com.br

${ }^{10}$ Universidade de São Paulo. E-mail: antonio.artur.santos@usp.br

${ }^{11}$ Universidade de São Paulo. E-mail: andrio.soares@usp.br

${ }^{12}$ Universidade de São Paulo. E-mail: hellenrgb@usp.br

${ }^{13}$ Universidade de São Paulo. E-mail: georgeamelo@usp.br

${ }^{14}$ Universidade de São Paulo.E-mail: rodrigo.ferreira.santos@usp.br
}

\begin{abstract}
RESUMO
Nos sopés das escarpas de cuesta, os modelados de relevo têm sua gênese atribuída a depósitos correlativos e alterações in situ, cujas interpretações baseiam-se na aloctonia ou autoctonia dos materiais. Propõe-se para este trabalho o estudo das formas e dos materiais à frente da escarpa da Serra de São Pedro-SP, permitindo entender a evolução geomorfológico-pedológica da área e uma melhor compreensão da relação entre modelado de relevo, processos e materiais na transição Planalto Ocidental - Depressão Periférica Paulista. Nesse contexto, optou-se pela investigação detalhada de uma vertente em um interflúvio localizado no sopé da escarpa, por meio análise em topossequência seguindo os princípios da Análise Estrutural da Cobertura Pedológica, desenvolvendo-se estudos macro e micromorfológicos, granulométricos, morfoscópicos, densimétricos, químicos, mineralógicos e geocronológicos dos materiais, além de considerarem-se aspectos estruturais e neotectônicos da região.
\end{abstract}

Palavras-chave: Evolução Geomorfológico-Pedológica; Aloctonia; Autoctonia.

\section{EVOLUTION OF RELIEF MODELING AND MATERIALS OF CUESTA CLIFF IN SÃO PEDRO-SP}

\begin{abstract}
In the cuesta escarpment foothills, landforms have their genesis attributed to correlative deposits and in situ alterations, whose interpretations are based on the allochthonous or autochthonous nature of the materials. It is proposed to study the landforms and materials in front of the Sao Pedro Ridge escarpment (SP), to understand the geomorphological-pedological evolution of the area and to achieve a better understanding of relationship between landforms, materials and processes in the transition of Western Plateau to Peripheral Depression of Sao Paulo. In this context, we choose for the detailed investigation a slope in an interfluve located at the foot of the


escarpment, through topossequence analysis following the principles of the Structural Analysis of the Pedological Cover, developing laboratory analysis (i.e., macro and micromorphological, chemical, mineralogical and geochronological studies), besides being considered structural and neotectonic aspects of the region.

Key-words: Geomorphological-Pedological Evolution; Allochthonous; Autochthonous

\section{INTRODUÇÃO}

Uma das formas de relevo da Bacia Sedimentar do Paraná mais expressivas são os relevos dissimétricos, compostos de um lado por uma vertente escarpada e de outro, no reverso, por uma rampa com mergulho suave. As escarpas de cuesta, situadas na transição da Depressão Periférica Paulista para o Planalto Ocidental do Estado de São Paulo, são alguns dos exemplos mais significativos destas morfologias (ALMEIDA, 1949).

As cuestas já foram alvo de diversos estudos geológico-geomorfológicos (TRICART, 1949; OBERLANDER, 1997; PENTEADO, 1983; GUTIÉRREZ, 2013), que discutiram seus mecanismos evolutivos em ambientes distintos. Uma feição geomorfológica muito comum às áreas de cuesta são os pedimentos, os quais desde os estudos clássicos de Gilbert (1877) e McGee (1896) são tidos como uma superfície de erosão formada sobre rochas menos resistentes. Esses autores admitem a ocorrência de recobrimento sedimentar sobre os pedimentos, tendo como fonte as áreas mais elevadas e íngremes compostas por rochas mais resistentes. Os pedimentos também são chamados de glacis (DRESCH, 1938), que os definiu como uma superfície suave ao pé de uma escarpa. Embora estas feições possam sugerir o transporte dos materiais que as superpõem, muitos estudos realizados com base na Análise Estrutural da Cobertura Pedológica, como os de Castro (1989), Dias Ferreira (1997), Furquim (2002), Michelon (2011) e Furquim et al. (2013), demonstram que estas descontinuidades também podem se formar in situ, não sendo, portanto, seguro utilizá-los como indicadores únicos do transporte e deposição dos materiais.

Nesse sentido, o estudo dos depósitos e mantos de alteração das regiões intertropicais reveste-se de grande complexidade quando se pretende desvendar mecanismos pretéritos determinantes da constituição e atributos que atualmente eles exibem. Embora o mecanismo evolutivo das áreas de serra ou bordas de planalto pareça conhecido e compatível com os modelos geomorfológicos consagrados que apontam o balanço morfogênese-pedogênese (BARBOSA, 1965; AB'SÁBER, 1969; AB'SÁBER, 1972), o estudo dos materiais da base das escarpas demonstra uma quase ausência dos depósitos correlativos, como foi verificado em muitas das pesquisas realizadas na região da Serra do Limoeiro em Bofete / SP (DIAS 
FERREIRA, 1978) e nas Serras de São Pedro e Itaqueri / SP (QUEIROZ NETO e JOURNAUX, 1978; DIAS FERREIRA, 1997; PINHEIRO, 2009 e 2014).

$\mathrm{Na}$ Serra de São Pedro, a pouca representatividade dos depósitos e a predominância de materiais de alteração autóctones coloca em dúvida os mecanismos da evolução geomorfológica da área. Igualmente, estudos sobre a tectônica da região também têm trazido nova luz acerca da geomorfologia da área: no reverso, a Neotectônica teria provocado movimentações verticais (falhas normais e inversas) e horizontais (transcorrências), registradas nas perturbações da Formação Itaqueri (LADEIRA e SANTOS, 2006; PINHEIRO, 2014). No glacis, assentado sobre arenitos triássicos da Formação Piramboia (ALMEIDA et al., 1981) e depósitos neocenozóicos de gênese não compreendida totalmente (MELO et al., 2001), a evolução teria sido influenciada pelo estabelecimento do sistema fluvial a partir dos planos de fraturamento, o que influenciou na dissecação do relevo.

Diante do exposto, objetiva-se na presente pesquisa a investigação da gênese dos materiais desses glacis, no sentido de determinar se são autóctones ou alóctones, quais são as suas relações com a evolução do relevo na região e como se configuraram as superfícies produzidas pelos processos atuantes no decorrer da história geológica. Assim, propõe-se para este trabalho o estudo das formas e dos materiais do glacis à frente da escarpa de cuesta da Serra de São Pedro / SP, cujos resultados permitirão entender a evolução geomorfológicopedológica da área por modelo genético-evolutivo e possibilitarão uma melhor compreensão da relação entre modelado de relevo, processos e materiais na transição Pl. Ocidental Depressão Periférica Paulista.

\section{MATERIAL E MÉTODOS}

A metodologia para execução do presente estudo baseia-se em alicerces que compõem a Geomorfologia e a Pedologia. Para a Geomorfologia, os estudos foram direcionados às vertentes, conexão dinâmica entre o topo do interflúvio e o fundo de vale (DYLIK, 1968), em que se considera esta como um corpo na superfície que é modelado por processos atuantes no presente e passado do tempo geológico. No âmbito da Pedologia, a investigação dos materiais e o consequente reconhecimento de processos e associação ao modelado de relevo tomarão como referência a Análise Estrutural da Cobertura Pedológica (BOULET, 1978). Esta metodologia tem como pressuposto a tridimensionalidade espacial das organizações 
pedológicas e suas estruturas, a dimensão temporal e o princípio de que a cobertura pedológica representa um contínuo nas vertentes, podendo ser analisada por meio de topossequência (QUEIROZ NETO, 2002).

Primeiramente, foi feito um levantamento bibliográfico acerca da área de estudo, bem como dos materiais cartográficos e produtos de sensoriamento remoto existentes sob o contexto regional. Posteriormente, foi escolhido um interflúvio do glacis para realização dos estudos de detalhe, baseada em trabalhos de campo exploratórios e análise integrada da carta geomorfológica de São Pedro (QUEIROZ NETO e JOURNAUX, 1978), mapa morfológico da região da Serra de São Pedro e do Baixo Piracicaba (PINHEIRO, 2014), imagens SRTM (Shuttle Radar Topography Mission) de resolução espacial de 30 m (USGS, 2014), e fotografias aéreas nas escalas 1:25.000 (1962) e 1: 30.000 (2006). A área de estudo se encontra delimitada na figura 1 .

Figura 1 - Localização da área de Estudo

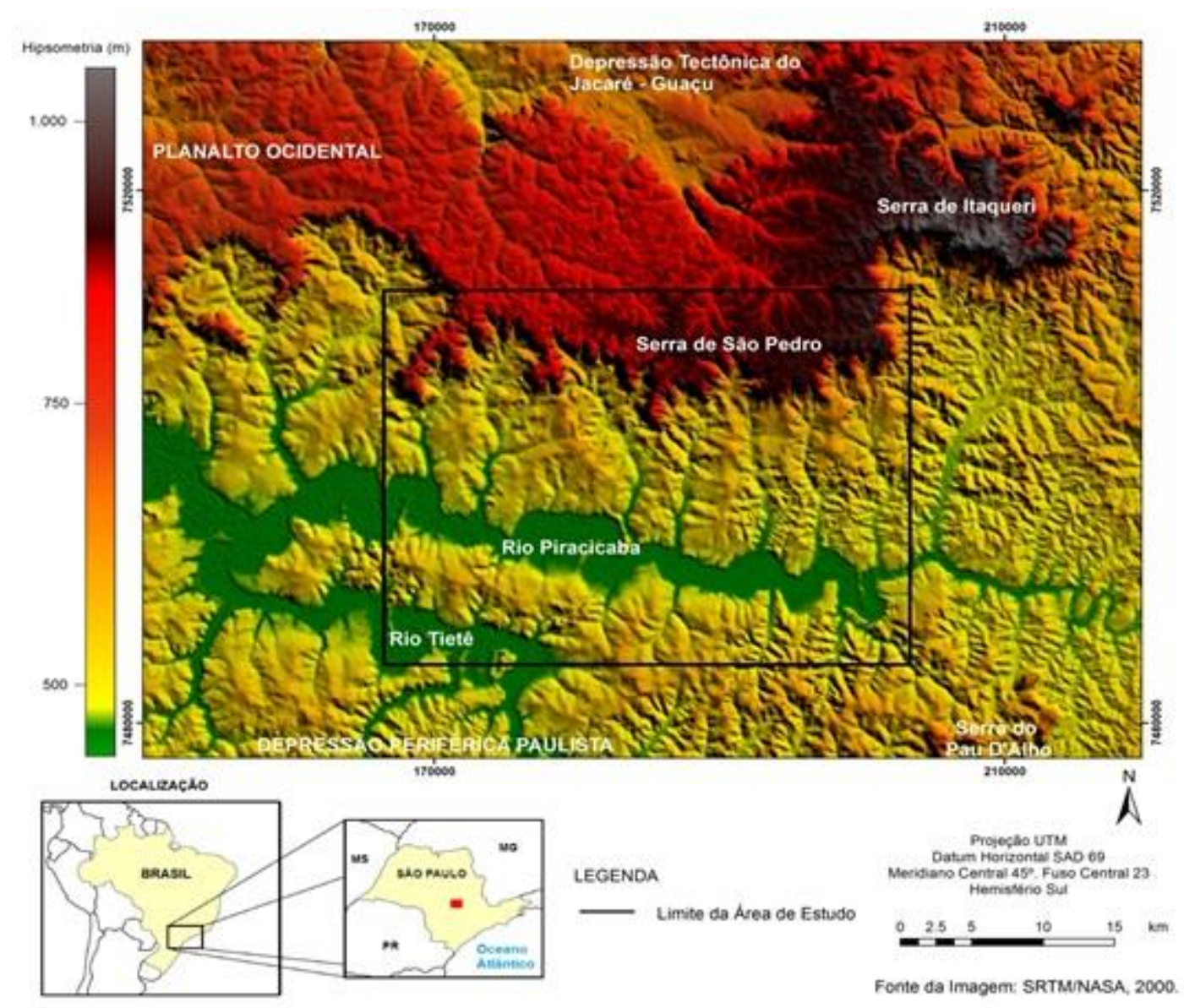

Fonte: Adaptado de PINHEIRO (2014). 
Efetuadas as seleções que envolvem escalas de menor detalhe, foi possível definir o eixo do levantamento em uma topossequência. Para tal, foram verificadas a morfologia de uma vertente do interflúvio segundo análise estereoscópica de fotografias aéreas, a presença de mudanças ou rupturas de declive que indicassem a variação da cobertura pedológica, também por tradagens expeditas, e acessibilidade.

Uma vez escolhido o eixo da topossequência, foi realizado o levantamento topográfico da vertente selecionada por meio do pantômetro (COLTRINARI, 2003), construindo a morfometria e morfologia detalhada da vertente. Em seguida, foram realizadas 11 sondagens manuais (tradagens) ao longo da topossequência (profundidades entre 6 e $8 \mathrm{~m}$ ), além da abertura de 5 trincheiras de $2 \mathrm{~m} 3$ cada e uma sondagem geológica no topo da vertente, até 20 $\mathrm{m}$ de profundidade. As tradagens foram executadas com o objetivo de identificar as principais características dos materiais, os limites dos grandes volumes/domínios pedológicos e as áreas de transição entre eles; as trincheiras foram realizadas para a observação do solo em perfil e coletas de amostras deformadas e indeformadas; e a sondagem geológica foi feita para verificar a que profundidade se dava a transição solo/alteração da rocha.

Nas trincheiras, as amostras, destinadas a análises laboratoriais foram coletadas tanto nos horizontes quanto nas transições entre os mesmos, e as descrições e coletas dos materiais em campo foram organizadas de acordo com Santos et al. (2013). As amostras coletadas foram encaminhadas a laboratórios para a realização de análises físicas (granulometria, porosidade, densimetria e morfoscopia), químicas (química total, complexo sortivo e grau de intemperismo), mineralógicas (difração dos raios X) e micromorfológicas, para confecção de lâminas delgadas e observação em microscópio ótico. Além destas análises (não finalizadas), foram realizadas 5 datações absolutas de materiais entre 1,5 e $2 \mathrm{~m}$ de profundidade, por meio das técnicas da Luminescência Opticamente Estimulada - LOE de cristais de quartzo, sendo possível desta maneira inferir-se a idade de eventos deposicionais quaternários (DULLER, 2004; SALLUN et al., 2007). O conjunto dos dados da pesquisa permitiu com que fossem apontadas a autoctonia / aloctonia dos materiais e a evolução geomorfológico-pedológica da região. 


\section{RESULTADOS E DISCUSSÕES}

O interflúvio escolhido para investigação por topossequência (denominada por Topossequência Campestre) caracteriza-se por vertentes com radiais e contornos convexos suaves, típicas de morfogênese trabalhada por escoamento superficial difuso (YOUNG, 1972; RUHE, 1975; COLANGELO, 2007; SMITH et al., 2011). Ainda, o interflúvio compõe divisor topográfico das bacias do Córrego Campestre e Ribeirão do Meio, configurando colina destacada na paisagem do glacis ao sopé da escarpa de cuesta de São Pedro. Por meio do levantamento com o pantômetro e análises morfológicas de tradagens e trincheiras foi possível apontar na Topossequência Campestre os setores de vertente (terço superior ou topo, terço médio, terço médio-inferior e terço inferior ou sopé) (Figura 2). O quadro verificado mostra que os materiais de cobertura do interflúvio estudado são predominantemente arenosos e homogêneos em profundidade (Figura 3).

Figura 2 - Perfil Topográfico da Topossequência Campestre, demonstrando os setores da vertente e as mudanças de declive

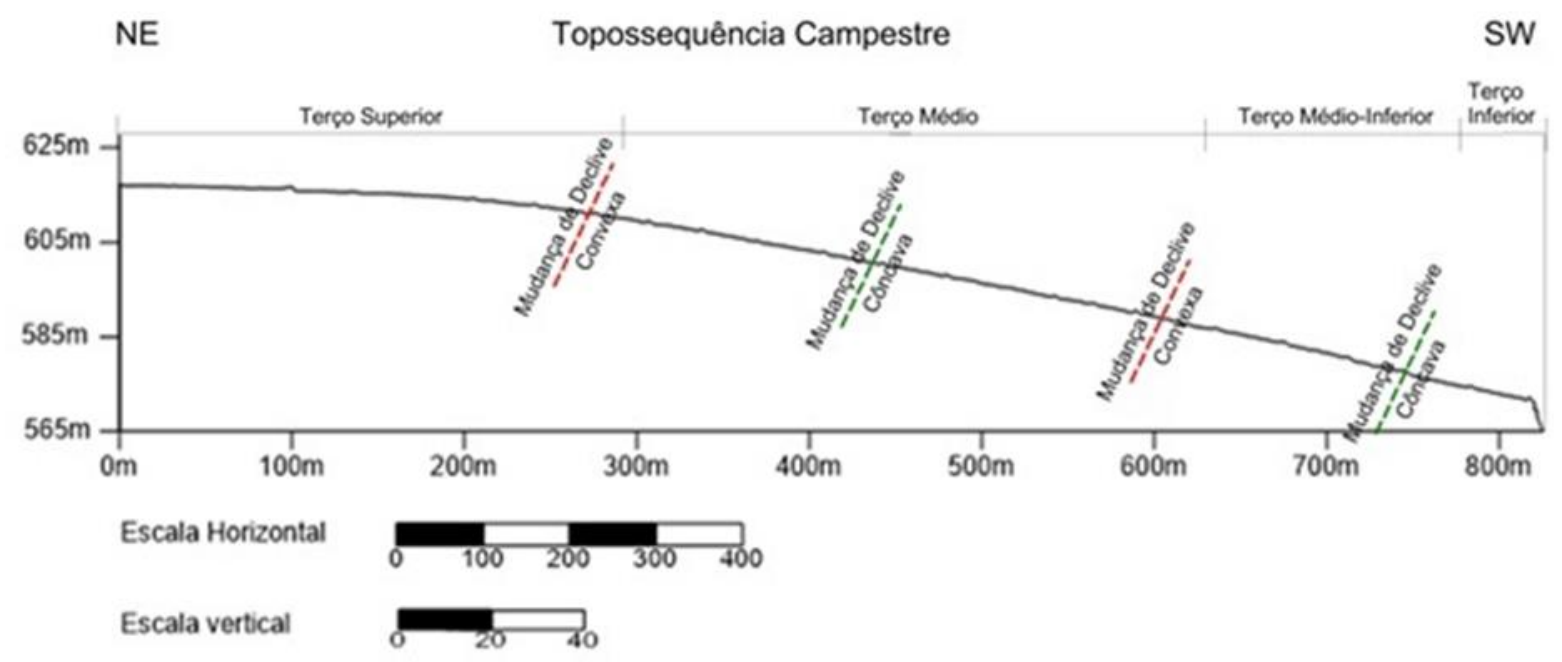

Fonte: Os Autores (2018). 
Figura 3 - Topossequência Campestre

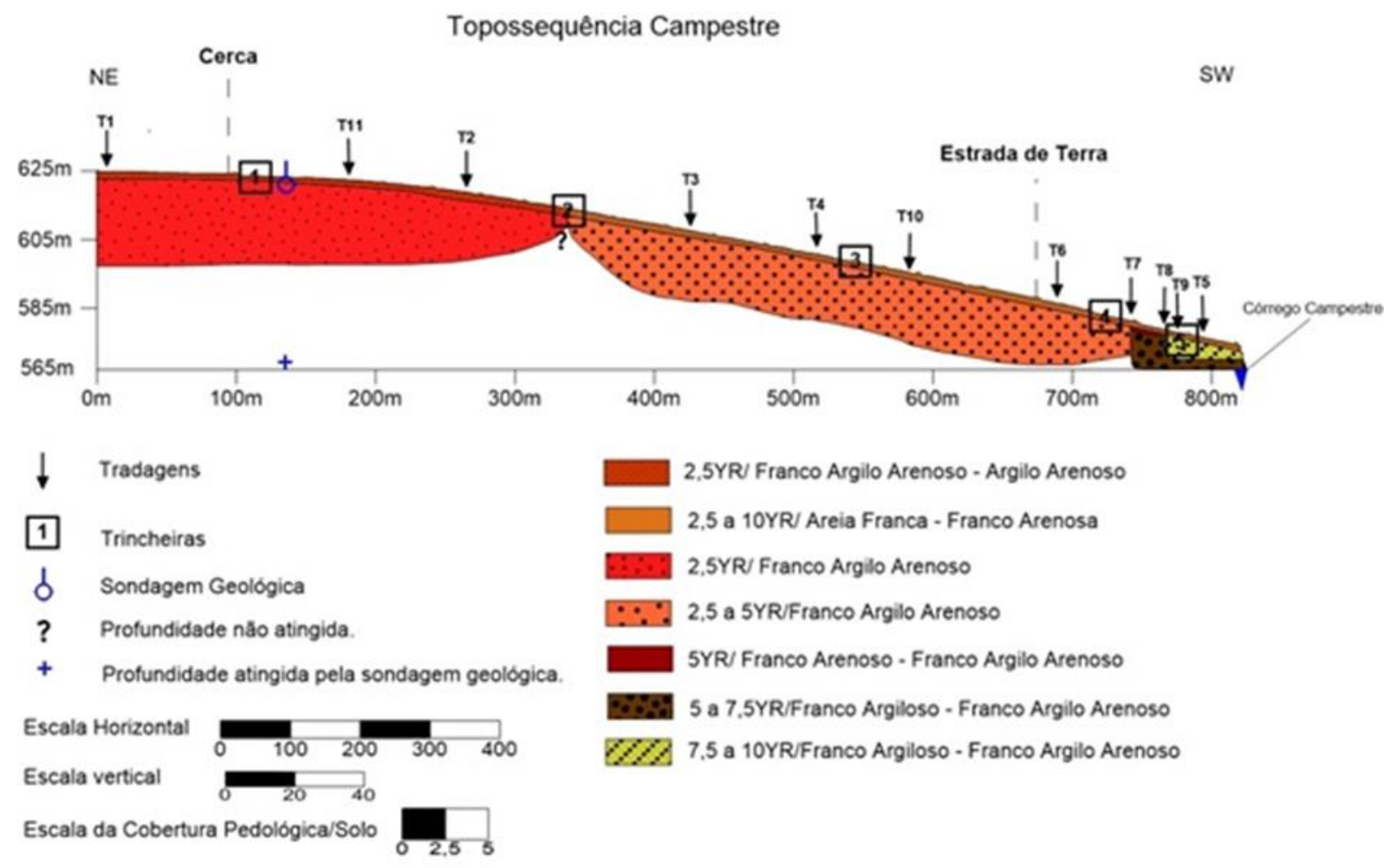

Fonte: Os Autores (2018).

Porém, apresentam diferenças laterais tênues ao longo da sequência, passando de um domínio de solos avermelhados e franco argilo-arenosos no topo para uma cobertura mais amarelada e ligeiramente menos argilosa nos terços superior a médio inferior da vertente. No sopé, os materiais apresentam gradiente textural abrupto em profundidade, cascalhos e seixos de litologias variadas, são mais amarelos e, à medida que se aproximam do nível d'água, surgem volumes mosqueados.

Esse quadro sugere que a cobertura pedológica do interflúvio não apresenta variações texturais em profundidade, mas, nos horizontes mais próximos da superfície, há gradiente textural. Tal gradiente é baixo na alta vertente e aumenta em direção ao sopé, tornando-se abrupto, sugerindo processos mais intensos de eluviação e iluviação. Essas variações podem ser decorrentes das possíveis alternâncias do funcionamento hídrico da vertente e do material de origem na base da topossequência.

As análises das trincheiras em questão (Figura 4) apontaram três domínios do sistema de transformação da Topossequência Campestre, a saber: - Um domínio no topo da vertente, com pedogênese avançando sobre material de origem arenoso, porém com certa quantidade de ferro e argila em razão dos matizes 2.5YR, presença de concreções ferruginosas 
magnetizadas e textura areia franca a franco argiloarenoso, onde os processos pedogenéticos permitem desenvolvimento da estrutura em blocos angulares.

Figura 4 - Trincheiras 1 a 5 da Topossequência Campestre

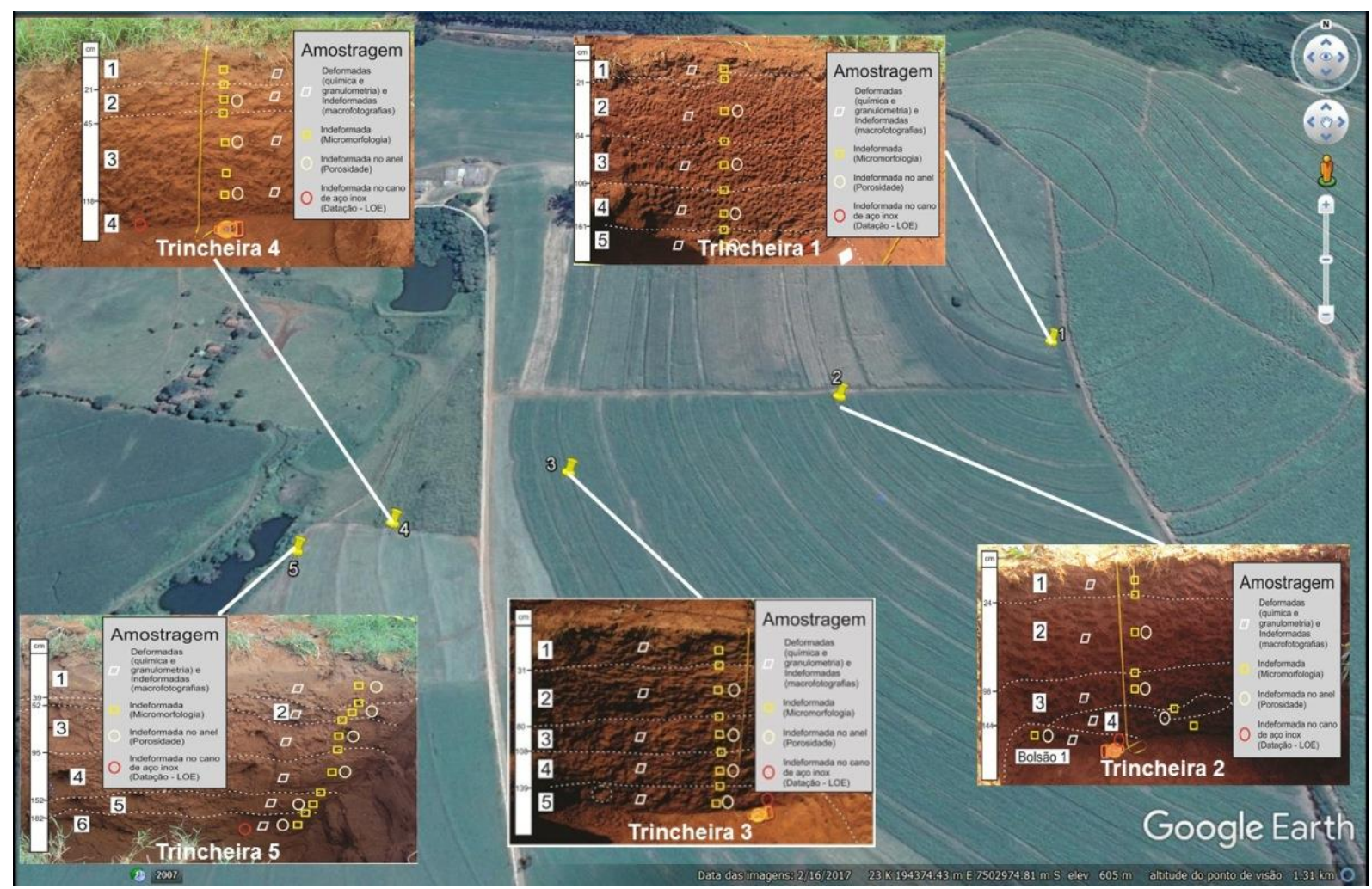

Fonte: Os Autores (2018).

Sua porosidade fissural aponta circulação interna desigual da água face à dessecação/umectação do perfil, havendo perda das frações finas em razão da existência de câmaras associadas à atividade biológica com areia lavada; - Um domínio no terço médio da vertente até o início do setor inferior, caracterizado pela circulação hídrica lateral e vertical desigual formando manchas e bolsões diferenciados em meio à matriz dos volumes, que varia nos matizes 2.5YR, 5YR e 7.5YR, com textura geralmente na classe franco argilo- arenoso e porosidade tubular e fissural associada à estrutura em blocos subangulares, com circulação hídrica interagregados formando feições indicadoras de perda de matéria; - Um domínio no terço inferior da vertente, com matizes na cor $7.5 \mathrm{YR}$, mas por vezes com tonalidades acinzentadas em volumes pequenos em meio à matriz dos volumes, predominando a textura franco argilo-arenoso e a estrutura em blocos subangulares, porém com gradiente textural entre os horizontes superiores, e inferiores e mudança de estrutura para granular, além da presença mais abundante de concreções, em geral não magnetizadas.

$\begin{array}{lll}\text { Villela et al, } 2018 & 138\end{array}$


Tais domínios do sistema de transformação detectados levam a crer haver um desenvolvimento diferenciado a montante da vertente, cuja gênese e dinâmica são ligadas às condições morfológicas do interflúvio e material de origem. Ao mesmo tempo, também há um domínio a jusante, mas de origem e dinâmicas diferentes daqueles existentes a montante. Entre ambos, o sistema de transformação no terço médio da vertente caracterizaria uma transição, estando aparentemente em desequilíbrio.

As análises granulométricas sugerem ligeira perda de argila dos horizontes superficiais (afetados pelo manejo) para os mais profundos em toda a vertente, ainda que a diferença textural entre estes não seja tão pronunciada até os volumes que compõem a Trincheira 4. Este processo de perda de argila é mais evidente apenas na baixa vertente, indicando que o processo se daria verticalmente, de cima pra baixo, e remontantemente, da baixa vertente em direção à alta.

Em relação à distribuição da fração areia, podem ser destacados três padrões encontrados: (1) predominância de areia de média à fina na alta vertente; (2) predominância de areia média na média vertente, mas com menor quantidade de areia fina em relação à alta vertente, e maior em relação à baixa, o que pode indicar uma transição; (3) predominância da fração média seguida pela fração grossa na baixa vertente.

Por fim, em relação ao material de origem do solo, é provável que este seja alóctone na base da vertente, a julgar pela variada litologia encontrada tanto nas frações arenosas como nos cascalhos e seixos. Essa hipótese sobre a aloctonia dos materiais do sopé da vertente é menos evidente nos outros pontos da sequência, uma vez que mesmo os materiais mais profundos do topo da vertente, obtidos pela sondagem, apresentam, por enquanto, origem bastante incerta.

Os dados das análises químicas mostram que os materiais estudados são geralmente bastante homogêneos em relação aos parâmetros químicos, apresentam baixa concentração de cátions básicos (desconsiderando os horizontes superficiais, mais modificados pelo manejo agrícola), eletronegativos, fracamente ácidos, com baixo teor de ferro, elevado grau de intemperismo e provável dominância de caulinita na fração argila. Esses dados deverão ser complementados e validados não apenas pelas análises químicas dos outros pontos como também pela difratometria de raios $\mathrm{X}$, que fornecerá indicativos preciosos sobre a assembleia mineralógica da fração coloidal.

Os resultados de datação apontam similaridade entre as idades de soterramento dos materiais do topo e da base da vertente. A amostra mais antiga da topossequência resultou em 
uma idade de $27.450 \pm 4.350$ anos no sopé da vertente (Trincheira 5). Esta foi seguida pela amostra no topo da vertente, com idade de $22.500 \pm 2.600$ anos (Trincheira 1). Próxima à Trincheira 1, a amostra da Trincheira 2, junto ao setor médio da vertente, obteve idade de $20.300 \pm 2.700$ anos; as idades mais recentes foram encontradas nas Trincheiras 3 (11.560 \pm 1.800 anos) e $4(13.460 \pm 1.410$ anos $)$, respectivamente no setor médio e na passagem do setor médio para a base da vertente.

As idades de soterramento tendem a avançar tanto em direção ao topo como em direção à base; desse modo, infere-se novamente o caráter transicional entre os setores de montante e jusante do interflúvio estudado. Além disso, as idades obtidas demonstram que o desenvolvimento da vertente onde se realizou o perfil em topossequência possui evolução associada ao Pleistoceno Superior no tocante aos materiais de até $2 \mathrm{~m}$ de cobertura, com as datações mais antigas correlacionadas ao Último Máximo Glacial - UMG nas regiões tropicais (SUGUIO, 2010; SOUZA e PEREZ FILHO, 2016; PINHEIRO e QUEIROZ NETO, 2017). Tais resultados expressam uma superfície cuja posição inicial foi desenvolvida sob condições climáticas mais secas e frias, que permitiram a deposição de mais de $2 \mathrm{~m}$ de espessura de material.

Após ser depositado, tal material sofreu intemperismo e pedogênese suficiente para, durante o aumento das condições de umidade no Holoceno, formar a cobertura pedológica mais desenvolvida no topo da vertente. Em outras palavras, os resultados sugerem que o desenvolvimento do modelado e materiais da topossequência conquistaram sua forma e cobertura atual por um processo agressivo e rápido de intemperismo e pedogênese no Quaternário tardio, enquanto que a erosão, em sua escultura pleistoceno superior/holocênica, foi marcada, provavelmente, por morfogênese mecânica menos agressiva.

\section{CONSIDERAÇÕES FINAIS}

Embora seja verificado o possível desenvolvimento mais recente da cobertura pedológica em razão da análise geomorfológica da vertente, análise estrutural da cobertura pedológica e datações, torna-se difícil sustentar somente uma possível autoctonia dos produtos de alteração dos materiais de origem. Sua gênese, alóctone, estaria associada à alteração de uma cobertura coluvial identificada na literatura por depósitos neocenozóicos no topo da vertente; na base da vertente investigada, haveria gênese também alóctone associada à alteração de depósitos fluviais. 
Tais apontamentos remetem à possibilidade do modelado de relevo e de sua cobertura pedológica no sopé da escarpa de cuesta de São Pedro-SP serem oriundos de depósitos mais recentes que constituíram cobertura coluvionar do glacis, intensamente atacados por intemperismo e pedogênese, além da morfogênese mecânica mais associada a fluxos difusos nas vertentes.

Há ainda a possibilidade de movimentação neotectônica vertical diferenciada de blocos que compõem a área induzir sedimentação e dissecação diferenciadas no glacis, se for considerado o eixo da cuesta até o Rio Piracicaba (movimentação a ser verificada em estudos futuros). Assim, são necessárias a agregação de análises faltantes e a investigação neotectônica da região de São Pedro-SP para que se construa um modelo geomorfológicopedológico genético-evolutivo da região mais fidedigno, escopo principal da presente pesquisa.

\section{AGRADECIMENTOS}

Os autores agradecem à FAPESP - Fundação de Amparo à Pesquisa do Estado de São Paulo pelo financiamento dos projetos vigentes "Evolução Geomorfológico- Pedológica de Sopés de Escarpas de Cuesta no Estado de São Paulo", na modalidade Auxílio à Pesquisa Regular (Processo 2016/08722-3), e "Neotectônica da Região da Serra de São Pedro e Arredores”, na modalidade Auxílio ao Pesquisador Visitante (Processo 2017/14791-0), este último em parceria com a Profa. Dra. Paola Cianfarra (Uniroma3, Itália).

\section{REFERENCIAS}

AB'SÁBER, A. N. Ritmo da Epirogênese Pós-Cretácica e Setores das Superfícies Neogênicas em São Paulo. Geomorfologia, São Paulo, n. 13, 1969, p. 1-20.

AB'SÁBER, A. N. Participação das Depressões Periféricas e Superfícies Aplainadas na Compartimentação do Planalto Brasileiro. Geomorfologia, São Paulo, n. 28, 1972, p. 1-38.

ALMEIDA, F. F. M. Relevo de Cuesta na Bacia Sedimentar do Rio Paraná. Boletim Paulista de Geografia, São Paulo, n. 3, p. 21-33, 1949.

ALMEIDA, F. F. M., HASUI, Y., PONÇANO, W. L., DANTAS, A. S. L., CARNEIRO, C. D. R., MELO, M. S., \& BISTRICHI, C. A. Mapa Geológico do Estado de São Paulo [Escala 1:500.000]. 2 volumes. São Paulo: Instituto de Pesquisas Tecnológicas. 1981.

BARBOSA, O. Quadro Provisório de Superfícies de Erosão e Aplainamento no Brasil (Inferências Paleoclimáticas e Econômicas). Revista Brasileira de Geografia, Rio de 
Janeiro, n. 4, v. 27, 1965, p. 641-642.

BOULET, R. Toposéquences de Sols Tropicaux en Haute Volta: Équilibres et Deséquilibres Pédobioclimatiques. Paris: Mémoires ORSTOM, v.85, 1978. 272 p.

CASTRO, S. S. Sistemas de Transformação Pedológica em Marília: B Latossólicos e B Texturais. São Paulo. 1989. 294 f. Tese (Doutorado) - Faculdade de Filosofia, Letras e Ciências Humanas, Universidade de São Paulo, São Paulo, 1989.

COLANGELO, A. C. Geomorfossíntese e Geomorfocinemática Aplicadas à Evolução e Estabilidade de Vertentes. 2007. 228 f. Tese (Livre Docência) - Faculdade de Filosofia, Letras e Ciências Humanas, Universidade de São Paulo, São Paulo, 2007.

COLTRINARI, L. Evolução Geomorfológica do Planalto de São José dos Campos (SP). 2003. 114 f. Tese (Livre Docência) - Faculdade de Filosofia, Letras e Ciências Humanas, Universidade de São Paulo, São Paulo, 2003.

DIAS FERREIRA, R. P. Geomorfologia da Região da Serra do Limoeiro. 1978. 152 f. Dissertação (Mestrado) - Faculdade de Filosofia, Letras e Ciências Humanas, Universidade de São Paulo, São Paulo, 1978.

DIAS FERREIRA, R. P. Solos e Morfogênese em São Pedro - SP. 1997. 157 f. Tese (Doutorado) - Faculdade de Filosofia, Letras e Ciências Humanas, Universidade de São Paulo, São Paulo, 1997.

DRESCH, J. Les Surfaces de Piémont Dans Les Djebilet et Le Massif Central du Grand Atlas. Compte Rendu Congress Internationale de Géographie, Amsterdam, v. 2, section 2a, 1938, p.135.

DULLER, G. A. T. Luminescence Dating of Quaternary Sediments: Recent Advances. Journal of Quaternary Science, n. 2, v. 19, 2004, p.183-192.

DYLIK, J. Notion du Versant en Geomorphologie. Bulletin de L'Academie Polonaise des Sciences, Série de Sciences Geol. et Geogr., n. 2, v. 16, 1968, p. 125-132.

FURQUIM, S. A. C. Interações Entre Modelado e Solo no Transecto Espraiado, São Pedro, SP. 2002. 170 f. Dissertação (Mestrado) - Faculdade de Filosofia, Letras e Ciências Humanas, Universidade de São Paulo, São Paulo, 2002.

FURQUiM, S. A. C.; COLTRINARI, L.; DIAS FERREIRA, R. P.; CASTRO, S. S.; PUGLIESE, G. R. Lamellae Formation Processes in Tropical Soils in Southeastern Brazil. Catena (Cremlingen), v. 107, 2013, p. 15-25.

GILBERT, G. K. Report on The Geology of The Henry Mountains (Utah). Washington DC: United States Geological and Geographical Survey, Rocky Mountain Region, v. 170. 1877. 
GUTIÉRREZ, M. Geomorphology. CRC Press, 2013. 1014p.

LADEIRA, F.S.B.; SANTOS, M. Tectonics and Cenozoic Paleosols in Itaqueri’s Hill (São Paulo-Brazil): Implications For The Long-Term Geomorphological Evolution. Zeitschrift fur Geomorphologie, v.145, n.10, 2006, p.37-62.

McGEE, W. J. Sheetflood Erosion. Geological Society of America Bulletin, n. 1, v. 8, p. 87$112,1896$.

MELO, M. S.; COIMBRA, A. M; CUCHIERATO, G. Genesis of Quaternary Colluvial Eluvial Sedimentary Covers in Southeastern Brazil. [Genèse de Couvertures Sédimentaires Colluvio-Eluviales Quaternaires au Sud-Est du Brésil]. Quaternaire, Volume 12, Número 3, 2001, p. 179-188.

MICHELON, C. R. Evolução de Sistemas de Solos Laterítico e Podzolizado: Inferências Sobre A Forma Atual da Vertente - Bacia do Alto Rio Preto - MG. 2011. 139 f. Tese (Doutorado) - Faculdade de Filosofia, Letras e Ciências Humanas, Universidade Estadual Paulista Júlio de Mesquita Filho, Instituto de Geociências e Ciências Exatas, Rio Claro, 2011. OBERLANDER, T. M. Slope and Pediment Systems. In: THOMAS, D. S. G. Arid Zone Geomorphology: Process, Form and Change in Drylands. Chichester: John Wiley and Sons, 1997, p. $135-163$.

PENTEADO, M. M. Fundamentos de Geomorfologia. Rio de Janeiro: IBGE, 1983. 185 p.

PINHEIRO, M. R. Técnicas Cartográficas e Aerofotogramétricas para o Estudo da Erosão: Alta Bacia do Ribeirão Araquá - São Pedro e Charqueada / SP. 2009. 186 f. Dissertação (Mestrado) - Faculdade de Filosofia, Letras e Ciências Humanas, Universidade de São Paulo, São Paulo, 2009.

PINHEIRO, M. R. Estudo Morfotectônico da Região da Serra de São Pedro e do Baixo Piracicaba/SP. 2014. 286 f. Tese (Doutorado) - Faculdade de Filosofia, Letras e Ciências Humanas, Universidade de São Paulo, São Paulo, 2014.

PINHEIRO, M. R.; QUEIROZ NETO, J. P. From The Semiarid Landscapes of Southwestern USA To The Wet Tropical Zone of Southeastern Brazil: Reflections On The Development of Cuestas, Pediments, and Talus. Earth-Science Reviews, v. 172, 2017, p. $27-42$.

QUEIROZ NeTO, J. P.; JOURNAUX, A. Carta Geomorfológica de São Pedro. Instituto de Geografia da Universidade de São Paulo, IGEOG-USP, São Paulo, 1978.

QUEIROZ NETO, J. P. Análise Estrutural da Cobertura Pedológica: Uma Experiência de Ensino e Pesquisa. Revista do Departamento de Geografia, São Paulo, n. 15, 2002, p. 77 90 . 
RUHE, R. V. Geomorphology: Geomorphic Processes and Surficial Geology. Boston: Houghton Mifflin Company, 1975. 246 p.

SALlUN, A. E. M.; SUGUIO, K.; TATUMI, S. H.; YEE, M.; SANTOS, J.; BARRETO, A. M. F. Datação Absoluta de Depósitos Quaternários Brasileiros por Luminescência. Revista Brasileira de Geociências, São Paulo, n. 2, v. 37, 2007, p. 402-413.

SANTOS, H. G.; JACOMINE, P. K. T.; ANJOS, L. H. C.; OLIVEIRA, V. A.; LUMBRERAS, J. F.; COELHO, M. R.; ALMEIDA, J. A.; CUNHA, T. J. F.; OLIVEIRA, J. B. Sistema Brasileiro de Classificação de Solos. Brasília, DF: Embrapa, 2013. 353 p.

SMITH, M. J.; PARON, P.; GRIFFITHS, J. S. Geomorphological Mapping: Methods and Applications. Oxford: Elsevier, 2011, 661 p.

SOUZA, A. O.; PEREZ FILHO, A. Mudanças na Dinâmica Fluvial da Bacia Hidrográfica do Ribeirão Araquá: Eventos Tectônicos e Climáticos no Quaternário. Geousp (USP), v. 20, 2016, p. 636-656.

SUGUIO, K. Geologia do Quaternário e Mudanças Ambientais. Ed. Oficina de Textos. São Paulo, SP, 2010.

TRICART, J. O Relevo de Cuestas. Boletim Geográfico, IBGE, ano VII, n. 80, 1949, p.885896.

UNITED STATES GEOLOGICAL SURVEY - USGS. 2014. Disponível em: https://lta.cr.usgs.gov/SRTM1Arc. Acesso em: 10 out. 2015.

YOUNG, A. Slopes. Edinburgh: Oliver and Boyd, 1972, 288 p. 